\title{
Равномерность рассева и интенсивность покрытия почвы центробежными распылителями разбрасывателей удобрений
}

\author{
В.И. Мельник ${ }^{1}$, М.Я. Довжик ${ }^{2}$, Б.Я. Татьянченкоо, А.А. Соларев ${ }^{2}$, А.Н. Калнагуз ${ }^{2}$ \\ ${ }^{1}$ Харьковский национальный университет сельского хозяйства, \\ имени Петра Василенко (е. Харьков, Украина), victor_melnik@ukr.net, ORCID: 0000-0002-1176-2831 \\ 2 Сумский национальный аграрный универсuтет, (е. Сумы, Украина), fakyltet-mex@ukr.net
}

\begin{abstract}
Удобрение играет крайне важную роль в погоне за максимальным урожаем, однако не стоит забывать и о системах распределения. Одной из важнейших характеристик является точность разбрасывания, так как неравномерность процесса может заметно снизить эффективность.

В статье рассмотрены условия достижения равномерности покрытия и его интенсивность в пределах обрабатываемой полосы, определены ширина полосы захвата почвы, покрываемой центробежными разбрасывателями удобрений.

Большая начальная скорость выбрасываемых частиц приводит до большой ширины полосы захвата почвы, обрабатываемой центробежными разбрасывателями удобрений, намного больше, чем у других конструкций подобного назначения. Равномерность распределения материала в пределах полосы достигается за счет совмещения точки контакта двух соседних фракелов рассеивания с точкой падения частицы, движущейся по баллистической траектории. Интенсивность покрытия почвы удобрением зависит от скорости движения агрегата в осевом направлении и производительности всей установки.

Наведена классификация техники для внесения удобрений. По типу вносимых удобрений существуют разбрасыватели для органических удобрений, минеральных и органно-минеральных. Технологический процесс внесения органических удобрений кузовными разбрасывателями заключается в подаче пластинчастым транспортёром всего объёма удобрений к распределяющим рабочим органам, установленным в задней части кузова.

Проанализированы научные работы по рассеиванию твердых частиц центробежными разбрасывателями удобрений, где подробно рассмотрены вопросы теории движения сыпучего материала по лопаткам центробежных аппаратов и его распределение по поверхности поля.

Исследование влияния формы лопатки на кинематические параметры движения частицы может быть полезным при проектировании соответствующих рабочих органов.
\end{abstract}

Ключевые слова. Траектория, интенсивность, плотность орошения, равномерность, ротор, сектор выброса, сектор рассеивания, центробежный разбрасыватель, ширина захвата.

Введение. Удовлетворение потребности населения в продуктах питания и промышленности в сырье связано с повышением урожайности сельскохозяйственных культур. Практика показывает, что более 50 \% прибавки урожая получают за счет внесения удобрений. Внесение удобрений - один из эффрективных методов сохранения и повышения плодородия почвы, и как следствие, получения более высоких урожаев с высокими показателями качества. От характера распределения дозы удобрений по полю зависит средняя урожайность сельскохозяйственных культур. Максимально возможные урожаи сельскохозяйственных культур можно получить только при совместном применении органических и минеральных удобрений. При этом минеральные удобрения в основном способствуют повышению урожайности. Органические удобрения, помимо повышения урожайности, улучшают структуру и плодородие почвы, способствуя увеличению содержания гумуса, что непременно сказывается на качестве продукции.

Техника для внесения удобрений классифицируется по нескольким признакам. По типу вносимых удобрений существуют разбрасыватели для органических удобрений, минеральных и органно-минеральных. Технологический процесс внесения органических удобрений кузовными разбрасывателями заключается в подаче пластинчастым транспортёром всего объёма удобрений к распределяющим рабочим органам, установленным в задней части кузова.

Постановка проблемы. Рассеиванию твердых частиц центробежными разбрасывателями посвящено очень много научных работ. Например, в книге [1] подробно рассмотрены вопросы теории движения сыпучего материала по лопаткам центробежных аппаратов и его распределе- 
ние по поверхности поля, предложены способы выбора параметров рабочих органов машин, исходя из требования равномерного распределения удобрений. Экспериментально получены данные о незначительной неравномерности распределения материала.

Анализ последних исследований и публикаций. В теории центробежных разбрасывателей уделяется много внимания форме лопаток, изогнутых в виде, так называемой, брахистохроны. Это кривая наибыстрейшего перемещения из одной точки поля в другую. В центробежных разбрасывателях твердых частиц это не дает существенного результата. В статье [2] показано, что наиболее рациональными являются прямые радиальные лопатки. Однако существуют работы [3, 4], посвященные разработке моделей движения частиц грунта по поверхности лопатки роторного грунтометателя, в которых использованы уравнения динамики движения в форме уравнений Лагранжа первого рода.

Работа [5] посвящена изучению движения материальной частицы по лопатке центробежного рассеивающего аппарата аналитическим способом, осуществлено численное интегрирование системы дифференциальных уравнений. В работе [6] показано, что единственным путем повышения производительности разбрасывателя остается увеличения рабочей ширины захвата машины. В работе [7] приведен анализ конструкции агрегатов для разбрасывания удобрений. В статье [8] изложены результаты теоретических исследований рассеивания удобрений центробежными рабочими органами и приведены результаты экспериментальных исследований. Показано, что на рабочей ширине захвата до 33 метров неравномерность рассева нитроаммофоски может достигать $14 \%$.

Результаты исследования движения материальных частиц по поверхностям лопаток центробежных роторов широко освещены в работах В.П. Горячкина, Л.Б. Левенсона, Б.А. Берга, П.М. Василенко, П.М. Заики и многих других ученых. Тем не менее, возникают вопросы, требующие дополнительного изучения. Например, остаются до конца не изученными причины неравномерности покрытия почвы при разбрасывании твердых материалов.

Постановка задачи. В настоящей работе приведен анализ причин неравномерности покрытия почвы удобрениями, предложен способ обеспечения более равномерного рассева.

Изложение основного материала. Центробежные разбрасыватели удобрений обычно оборудованы двумя роторами, вращающимися в противоположных направлениях в плоскости, наклоненной под некоторым углом $\alpha$ (рис. 1) к горизонтальной поверхности. Основные преимущества таких аппаратов - высокая производительность и большая ширина орошаемой полосы.
Оба вращающихся диска оснащены прямолинейными лопатками, количество которых, как правило, равно четырем, но возможны и другие варианты. Диски ограждены по контуру кольцевыми стенками, препятствующими произвольному выбросу материала, но имеют окна для направленного выбрасывания частиц. Назовем часть круга, ограниченную радиусами на границах такого окна сектором выброса. Как известно, твердая частица, покидающая диск, имеет переносную скорость $U_{e}$ (рис. 1, 2), касательную к окружности, и относительную скорость $U_{r}$, направленную радиально. Возможен случай, когда эти две скорости равны, если не учитывать трения и частица начинает свой путь с центра круга с нулевой скоростью. Но обычно по разным причинам $U_{r}<U_{e}$, и тогда суммарная начальная скорость $U_{0}$, равная геометрической суме этих двух слагаемых, составляет некоторый острый угол $\theta$ с направлением переносной скорости $\cup_{e} . \mathrm{V}$ существующих навозоразбрасывателей $U_{r}$ в среднем меньше чем $U_{e}$, примерно в 3,0 - 3,5 раза и составляет около 4,0 - 4,5 м/с.

Центральный угол $\varphi$ сектора выброса можно представить в виде суммы $\varphi=\varphi_{1}+\varphi_{2}$, где $\varphi_{1}-$ угол между линией оси машины и крайним радиусом сектора выброса со стороны соседнего ротора. Два направления начальной скорости $\cup_{0}$ на краях дуги $A B$ сектора выброса образуют так называемый сектор рассеивания с центральным углом $\varphi$.

Точки $A_{1}$ и $B_{1}$ соответствуют граничным положениям дуги сектора рассеивания, а точка $C$ находится посередине дуги сектора выброса и ей соответствует точка падения частиц $C_{1}$.

Единого центра сектора рассеивания не существует. Положение центра кривизны кривой $A_{1} B_{1}$ меняется, но сам радиус кривизны $R$ остается постоянным. Его можно принять равным $x_{\max }$ - максимальной абсциссе баллистической траектории полета частицы, построенной в системе координатах $x-y$. Если пренебречь сопротивлением воздуха, то вершина параболы находится в точке с максимальной ординатой уmаx.

Дуга $A_{1} B_{1}$ является геометрическим местом точек падения частиц разбрасываемого материала. Она определяет ширину обработанной одним ротором полосы. Два фракела секторов рассеивания определяют ширину захвата орошаемой агрегатом почвы. Ширина захвата равна $2 L$; $x_{\max }=R ; \operatorname{tg} \theta=U_{r} / U_{e}$.

Очевидно, что в пределах угла рассеивания материал распределяется по дуге $A_{1} B_{1}$ равномерно. Проблемы возникают на стыке соседних секторов рассеивания. Если они перекрывают друг друга, появляется участок с удвоенной плотностью орошения. Если же два соседних сектора рассеивания расходятся, то будут иметь место участки, на которые материал не попадает совсем. Таким образом, задача обеспечения равномерности рассева решается 
довольно просто - необходимо лишь обеспечить контакт крайних точек дуг $A_{1} B_{1}$ двух секторов рассеивания в точках падения частиц, движущихся по баллистической траектории. Так решается задача о равномерности распределения разбрасываемого материала в пределах всей ширины полосы захвата

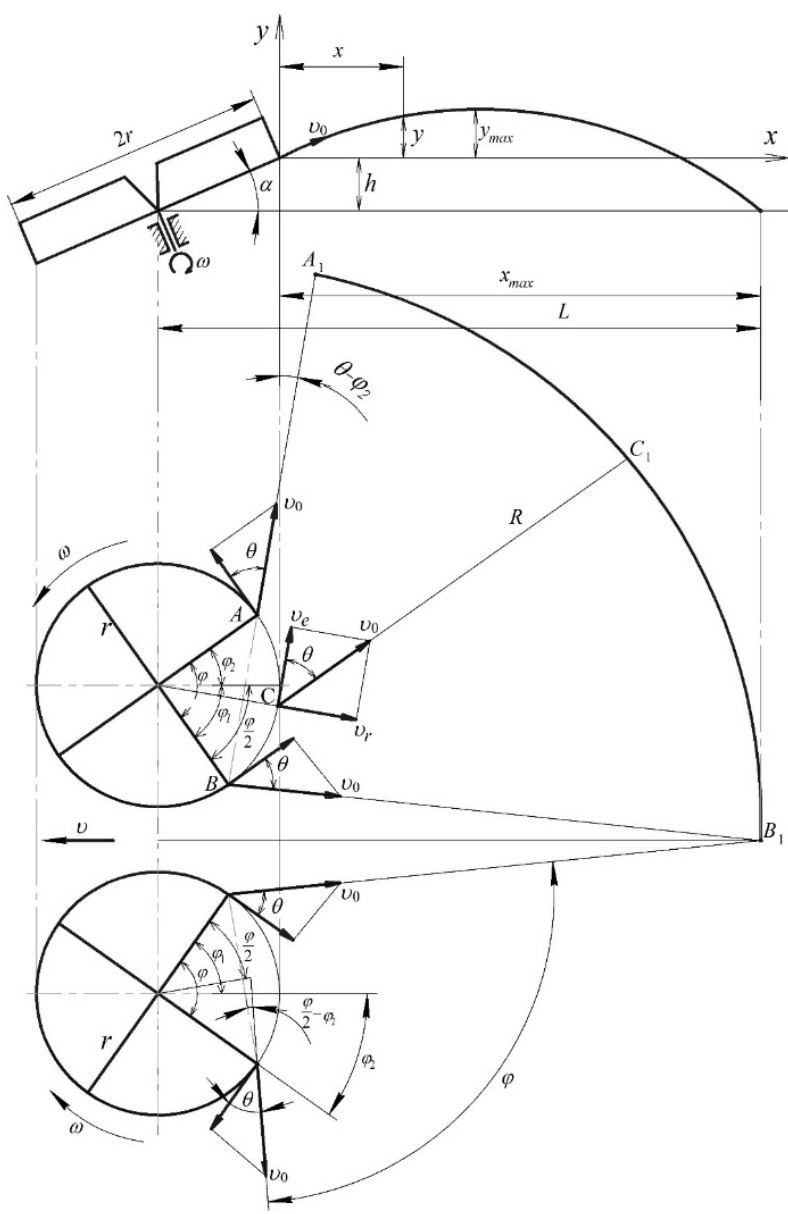

Рис. 1. Схема обработки почвы двумя спаренными четырехлопастными центробежными разбрасывателями удобрений

Интенсивность покрытия почвы удобрением определяется, с одной стороны, производительностью установки, главным образом, центробежных распылителей и, с другой стороны, скоростью движения агрегата $U$. Если $\mathrm{mg}$ - производительность установки в весовых единицах, а $\Delta t-$ время перемещения агрегата в направлении движения за один оборот ротора, то интенсивность орошения в весовых единицах будет равна

$$
q_{\mathrm{e}}=\frac{m g}{L v \Delta t}, \quad\left(\frac{H}{M^{2}}\right)
$$

или в массовых единицах

$$
q_{M}=\frac{m}{L v \Delta t}, \quad\left(\frac{\kappa 2}{M^{2}}\right),
$$

где

$$
\begin{gathered}
L=2 r \sin \frac{\phi}{2} \cos \left(\frac{\phi}{2}-\phi_{2}\right) \cos \alpha+ \\
+x_{\max } \cos \left(\theta-\phi_{2}\right)
\end{gathered}
$$

- ширина захвата одного факела.

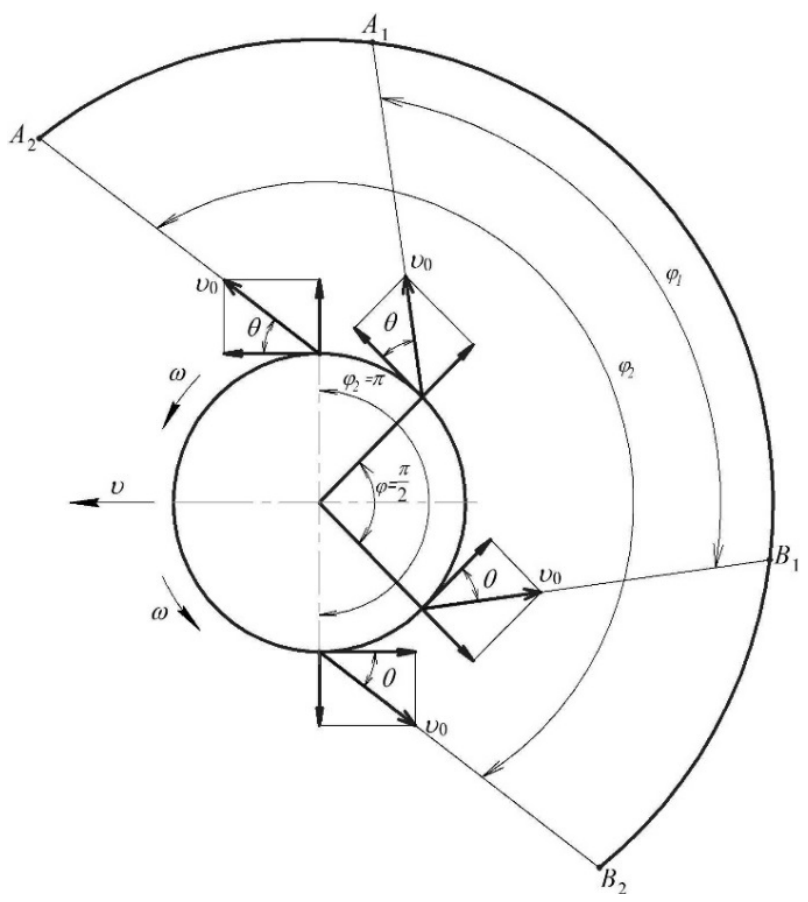

Рис. 2. К выбору размеров сектора выброса

Выбор центрального угла сектора выброса это задача на оптимизацию. Обычно стремятся делать его по возможности большим. Но из рисунка 2 видно, что сектор выброса с центральным углом $\pi / 2$ позволяет достичь равномерности рассева, обеспечив контакт с соседним факелом в точке $B_{1}$, однако ширина полосы захвата в этом случае будет значительно меньше, чем в случае когда центральный угол сектора выброса принять равным $\pi$. Но тогда значительная часть материала летит против движения агрегата и почти невозможно обеспечить контакт двух фракелов рассеивания в точке $B_{2}$, О равномерности рассева в этом случае говорить не приходится, хотя ширина полосы здесь большая.

Выводы. Ширина полосы захвата почвы, обрабатываемой центробежными разбрасывателями удобрений, намного больше, чем у других конструкций подобного назначения, что достигается за счет большой начальной скорости выбрасываемых частиц. Это одно из важнейших преимуществ таких разбрасывателей. Равномерность распределения материала в пределах полосы достигается за счет совмещения точки контакта двух соседних факелов рассеивания с точкой падения частицы, движущейся по баллис- 
тической траектории. Интенсивность покрытия почвы удобрением зависит от скорости движения агрегата в осевом направлении и производительности всей установки.

\section{Литература}

1. Черноволов В.А. Моделирование процессов распределения минеральных удобрений центробежными аппаратами монография / B.A. Черноволов, Т.М. Ужахов. - М-во сел. хоз-ва Рос. Федерации, Федер. гос. образ: Зерноград [Рост. обл.], 2011. - 264 с.

2. Татьянченко Б. Я. Путешествие брахистохроны / Б. Я. Татьянченко, М. Я. Довжик, А. Н. Калнагуз. // Республиканское унитарное предприятие «Научно-практический центр Национальной академии наук Беларуси по механизации сельского хозяйства». Минск «Беларуская навука». - 2018. - С. 274-281.

3. Шатохин В.М. Моделирование движения частицы грунта по шероховатой поверхности пространственной лопатки роторного грунтометателя / В.М. Шатохин, Н.В. Шатохина, А.Н Попова // Строительство и техногенная безопасность. - Симферополь : СМКУ. - 2014. - Вип.48. - C. 201-210.

4. Семкив О. М. Исследование движения частицы грунта по лопатке с профилем оптимальной фрормы в поле центробежных сил инерции [Электронный ресурс] / О. М. Семкив, В. М. Шатохин, А. Н. Попова // Технічна естетика і дизайн.2012.- Вип. 11.- С. 165-174. - Режим доступу: http://nbuv.gov.ua/UJRN/texnect_2012_11_30.

5. Пилипака С.Ф. Дослідження руху матеріальної частинки добрива при відцентровому розсіюванні / С.Ф.Пилипака, В.В.Яременко, О.М.Черниш, О. В. Адамчук // Конструювання, виробництво та експлуатація сільськогосподарських машин. - 2013. - Вип. 43(1). - С. 127-136. - Режим доступу: http://nbuv.gov.ua/UJRN/Zmntz_2013_43(1)_19.

6. Адамчук О. Теория разгона удобрений рассеивающим рабочим органом центробежного типа [Электронный ресурс] / О. Адамчук // Научни трудове на Русенския університет. - 2013. - Т. 52, серия 1. - С. 22-30. Режим доступу: http://conf.un i-ruse.bg/bg/docs/cp13/1.1/1.1-3.pdf

7. Прасолов $€$. Я. Вдосконалення агрегату для розкидання мінеральних добрив / Є. Я. Прасолов, Є.В. Педора, Я.А. Бочарова // Вісник Національного технічного університету "ХПІ". Сер.: Нові рішення в сучасних технологіях. - 2013. - № 38 (1011). - С. 26-33. - Режим доступу: http://nbuv.gov.ua/UJRN/vcpinrct_2013_38_6.

8. Адамчук В. Математическая модель разбрасывания минеральных удобрений центробежным способом [Электронный ресурс] / В. Адамчук, В. Яременко, Н. Борис // Agricultural
Engineering, Research Papers. Vol. 45 Issue 1, p614.9p. - 2013. - Режим доступу до ресурсу: http://ageng.asu.It/ae/article/download/14/28.

\section{References}

1. Chernovolov, V. and Uzhahov, T. (2011). Modelirovanie processov raspredelenija mineral'nyh udobrenij centrobezhnymi apparatami monografija. Zernograd: Ministry of Agriculture of the Russian Federation, p.264.

2. Tatyanchenko, B., Dovzhik, M. and Kalnaguz, A. (2018). The travel of the brahistrochrone. Mehanizacia i elecrtificacia sel'skogo hozyajstva, [online] (51), pp.274-281. Available at: https://elibrary.r u/item. asp?id=32699354 [Accessed 6 Nov. 2019].

3. Shatohin, V., Shatohina, N. and Popova, A. (2013). Modelirovanie dvizhenija chasticy grunta po sherohovatoj poverhnosti prostranstvennoj lopatki rotornogo gruntometatelja. Stroitel'stvo i tehnogennaja bezopasnost'. Krymskij federal'nyj universitet im. V.I. Vernadskogo (Simferopol'), [online] (48), pp.201-210. Available at: https://elibrary.ru [Accessed 6 Nov. 2019].

4. Semkiv, O., Shatohin, V. and Popova, A. (2012). Issledovanie dvizhenija chasticy grunta po lopatke $s$ profilem optimal'noj formy $v$ pole centrobezhnyh sil inercii. [online] http://www.irbisnbuv.gov.ua/. Available at: http://nbuv.gov.ua/UJR N/texnect_2012_11_30 [Accessed 6 Nov. 2019].

5. Pylypaka, S., Yaremenko, V., Chernysh, O. and Adamchuk, O. (2013). Doslidzhennia rukhu materialnoi chastynky dobryva pry vidtsentrovomu rozsiiuvanni. Konstruiuvannia, vyrobnytstvo ta ekspluatatsiia silskohospodarskykh mashyn., [online] 1(Vyp. 43), pp. 127-136. Available at: http://www.irbis-nbuv.gov.ua [Accessed 6 Nov. 2019].

6. Adamchuk, O. (2013). Teorija razgona udobrenij rasseivajushhim rabochim organom centrobezhnogo tipa.. 1st ed. [ebook] Minsk: Nauchni trudove na rusenskija universitet, pp.22-30. Available at: http://conf.uni-ruse.bg/bg/docs/cp13/1.1/1.13.pdf [Accessed 6 Nov. 2019].

7. Prasolov, Y., Pedora, Y. and Bocharova, Y. (2013). Vdoskonalennia ahrehatu dlia rozkydannia mineralnykh dobryv. isnyk Natsionalnoho tekhnichnoho universytetu "KhPl". Seriia : Novi rishennia $v$ suchasnykh tekhnolohiiakh, [online] (№ 38), pp.2633. Available at: http://www.irbis-nbuv.gov.ua [Accessed 6 Nov. 2019].

8. Adamchuk, V., Jaremenko, V. and Boris, N. (2013). Mathematical model of spreading fertilizers centrifugally - PDF. [online] Docplayer.ru. Available at: https: //docplayer.ru/74199663-Matematicheskaya -model -razbrasyvaniya-mineralnyh-udobreniycentrobezhnym -sposobom -mathematical-modelof-spreading-fertilizers-centrifugally.html [Accessed 6 Nov. 2019]. 


\title{
Анотація
}

\section{Рівномірність розсіву та інтенсивність покриття ґрунту відцентровими розпилювачами родкидачів добрив}

\author{
В.І. Мельник, М.Я. Довжик, Б.Я. Татьянченко, О.О. Соларьов, О.М. Калнагуз
}

Добриво відіграє важливу роль у погоні за максимальним урожаєм, однак не варто забувати й про системи розподілу. Однією з найважливіших характеристик $€$ точність розкидання, тому що нерівномірність процесу може помітно знизити ефективність.

У статті розглянуті умови досягнення рівномірності покриття і його інтенсивність, у межах оброблюваної смуги, визначена ширина смуги захвата ґрунту, що покривається відцентровими розкидачами добрив. Більша початкова швидкість часток, що викидаються, приводить до великої ширини захвата ґрунту, оброблюваної відцентровими розкидачами добрив, набагато більше, ніж в інших конструкцій подібного призначення. Рівномірність розподілу матеріалу в межах смуги досягається за рахунок сполучення крапки контакту двох сусідніх фракелів розсіювання із точкою падіння частки, що рухається по балістичній траєкторії. Інтенсивність покриття ґрунту добривом залежить від швидкості руху агрегату в осьовому напрямку та продуктивності всієї установки.

Наведено класифрікацію техніки для внесення добрив. По типу внесених добрив існують розкидачі для органічних добрив, мінеральних і органно-мінеральних. Технологічний процес внесення органічних добрив кузовными розкидачами полягає в подачі пластинчастим транспортером усього обсягу добрив до робочих органів, що розподіляють, установленим у задній частині кузова.

Проаналізовано наукові праці по розсіюванню твердих часток відцентровими розкидачами добрив, де докладно розглянуті питання теорії руху сипучого матеріалу по лопатках відцентрових апаратів і його розподіл по поверхні поля. Дослідження впливу фоорми лопатки на кінематичні параметри руху частки може бути корисним при проектуванні відповідних робочих органів.

Ключові слова: траєкторія, інтенсивність, щільність зрошення, рівномірність, ротор, сектор викиду, сектор розсіювання, відцентровий розкидач, ширина захвату.

\section{Abstract}

\section{Size uniformity and soil coating intensity by centrifugal sprayers of fertilizers}

\section{V.I. Melnik, M.J. Dovzhik, B.J. Tatyanchenko, A.A. Solarov, O.M. Kalnahuz}

Fertilizer plays an extremely important role in the pursuit of maximum yield, but do not forget about distribution systems. One of the most important characteristics is the accuracy of the spread, since the unevenness of the process can significantly reduce the efficiency.

The article considers the conditions for achieving uniformity of coverage and its intensity within the treated strip, determines the width of the soil capture strip covered by centrifugal fertilizer spreaders. The high initial velocity of the ejected particles leads to a large width of the soil capture band treated by centrifugal fertilizer spreaders, much more than other designs for this purpose. The uniformity of the distribution of material within the strip is achieved by combining the contact point of two adjacent scattering plumes with the point of incidence of a particle moving along a ballistic trajectory. The intensity of soil fertilization by fertilizer depends on the speed of the unit in the axial direction and the productivity of the entire installation.

A classification of fertilizer equipment has been introduced. According to the type of fertilizer applied, there are spreaders for organic fertilizers, mineral and organic-mineral. The technological process of applying organic fertilizers with body spreaders consists in feeding the entire volume of fertilizer to the distributing working bodies installed in the rear of the body by the plate-conveyor.

The scientific work on the dispersion of solid particles by centrifugal fertilizer spreaders is analyzed, where the theory of the movement of bulk material along the blades of centrifugal apparatuses and its distribution over the field surface are examined in detail. The study of the influence of the shape of the blade on the kinematic parameters of particle motion can be useful in the design of the corresponding working bodies.

Keywords: Trajectory, intensity, irrigation density, uniformity, rotor, ejection sector, dispersion sector, centrifugal spreader, working width.

Бібліографічне посилання/ Bibliography citation: Harvard

Melnik, V., Dovzhik, M., Tatyanchenko, B., Solarov, A. and Kalnahuz, O. (2019). Size uniformity and soil coating intensity by centrifugal sprayers of fertilizers. Engineering of nature management, (3(13), pp. $51-55$.

Подано до редакції / Received: 16.10.2019

ISSN 2311-1828

http://enm.khntusg.com.ua
Інженерія природокористування, 2019, №3(13), с. 51 - 55

Engineering of nature management, 2019, \#3(13), p. 51 - 55 